\title{
Microbiology Specimen Sequence Number
}

National Cancer Institute

\section{Source}

National Cancer Institute. Microbiology Specimen Sequence Number. NCI Thesaurus.

Code C87917.

A number that identifies the ordering relations (in time, space, etc.) in a set of microbiology specimens. 